\title{
Vibration Analysis of a Turbulent Fluid Passing Inside an Elbow Shaped Pipe Section
}

\section{Keshtkar $\mathrm{H}^{*}$ and Jafari AA}

Iran University of Science and Technology, Karaj, Iran

\begin{abstract}
Fluids being passing through a pipeline system can cause internal vibrations within the pipelines. If these vibrations weren't considered at the design of the system, and flow induced vibrations resonate with the pipes natural frequency, the sudden amplified vibrations can cause destructive damage to the pipeline system. Thus, it is extremely important to identify and predict all vibrations a certain pipeline system will possibly encounter during its lifetime when designing the system, also choosing the proper material with regard to their natural frequencies to avoid destructive resonances from happening. In this study, using ABAQUS as a CFD solver, we studied the forced and free vibrations caused by a turbulence flow of a fluid with different speeds through a 90 degree bent elbow pipe. We compared the vibration modes and frequencies for different cases of fluid speeds, and concluded at what natural frequency a vibration resonance may occur leading to a possible pipe failure.
\end{abstract}

Keywords: Fluid; Vibration

\section{Introduction}

With widespread industrial and scientific application of pipelines for different purposes of fluid transport, sometimes flammable and even explosive, it is of utmost importance to design the pipeline system in an effectively safe and secure manner. In 1974 more than \$114 million of damaged was caused to a U.S oil refinery site by an explosion within one of its major pipelines [1]. Rapid vibration in a high-energy pipeline (pipe carrying a fluid with high-energy) is always a major cause for pipeline failure, and when it's transporting highly flammable fluid, a catastrophic accident is waiting to happen if counter-measure aren't taken properly.

The most commonly cause for pipe vibration is due to the fluid suddenly changing its flow direction, for example in a pipe bend, causing a sudden direction to change in fluid flow velocity which leads to inverse pressure gradient caused by the turn, increasing fluid particle velocity towards the outside of the curvature. Also reducing the fluid particles velocity towards the inside of the turn, which in turn causes a stress and pressure gradient to form inside the pipeline. In addition, when a flowing fluid passes through a bend or a turn in a pipe, it produces a flow known as 'secondary flow' inside the pipe; creating a stress distribution inside the pipe body at the bend. This stress inflicted tends to deform the pipe and because the pipe bend section has been fixed at both ends, if the deformation forces are great enough can cause pipe rupture. Even if the stress imposed doesn't cause a rupture directly, it could build vibrations inside the flow; knowing fluids tend to have a low vibration damping capability in general, a vibration cause in one section can reach long distances downstream, resulting for a possible vibration resonance where ever it matches the natural frequency of the pipeline. A resonance within a pipe section, also leads to great vibrations building tension and strain within the section, and if the deformations are great enough it could cause it to fail (Figures 1-8).

The dynamic effect of fluid flow through shells has been studied by Klosowski, analyzing the damping capabilities of visco-elastic shells and plates [2].

And an in-depth study has been made by Qatu on the effect of straight pipe line vibration with relation to its material and coarseness [3].
Abraham et al. investigated the vibration and stability of straight pipelines in both steady flow and turbulence flow cases. Abraham considered the pipe bearings as linear and torsion springs, and investigated the effect of vibration damping implied on the springs. He then concluded that the position and properties of the pipe bearings can greatly affect the overall vibration generated and effect the pipes dynamic behavior [4].

Chen et al. analyzed the effect of shell thickness against free vibrations in both circular and non-circular pipe sections. Then she used

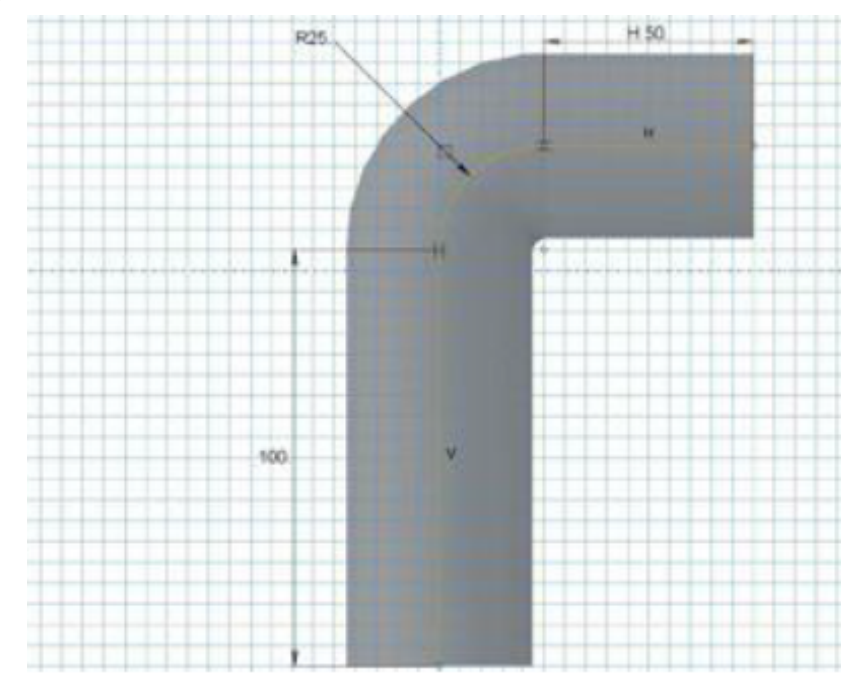

Figure 1: 2-dimension view of the elbow pipe modelled.

${ }^{*}$ Corresponding author: Keshtkar $\mathrm{H}$, Iran University of Science and Technology, Karaj, Iran, Tel: +98 217724 0540; E-mail: hosseinkeshtkar12@hotmail.com

Received May 12, 2017; Accepted June 30, 2017; Published July 04, 2017

Citation: Keshtkar H, Jafari AA (2017) Vibration Analysis of a Turbulent Fluid Passing Inside an Elbow Shaped Pipe Section. J Appl Mech Eng 6: 273. doi: 10.4172/2168-9873.1000273

Copyright: @ $\odot 2017$ Keshtkar, et al. This is an open-access article distributed under the terms of the Creative Commons Attribution License, which permits unrestricted use, distribution, and reproduction in any medium, provided the original author and source are credited. 


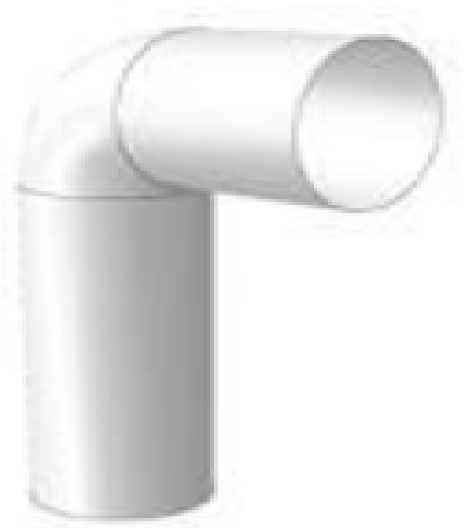

Figure 2: Pipe model, a hollow shell as specified below.

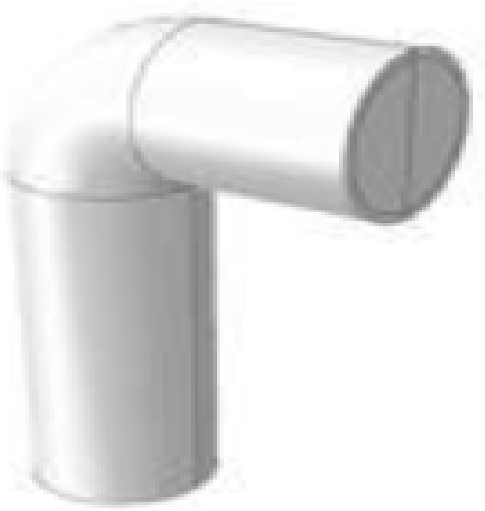

Figure 3: Fluid model, a filled geometry fitting exactly inside the pipe shell.

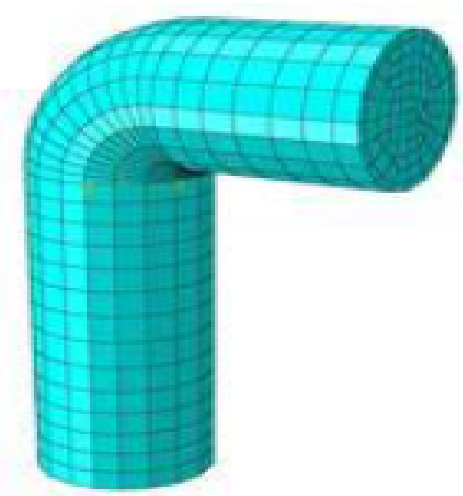

Figure 4: Meshed, combined fluid and pipe model.

finite element methods to calculate the natural frequency and vibration mode shapes for each different case. She concluded finite element method is an adequate approach to analyze and compute shell vibration, calculating its natural frequency and vibration mode shape [5].

Considering the extremely wide usage of pipelines in the modern world, it is essential to calculate beforehand and correctly identify the natural and forced vibrations that a pipeline system will encounter during its duty. In order to prevent accident caused by pipe failure, it is extremely important to prevent vibration from resonating inside pipe sections, by understanding the vibration amplitudes and containing them within safe limits.

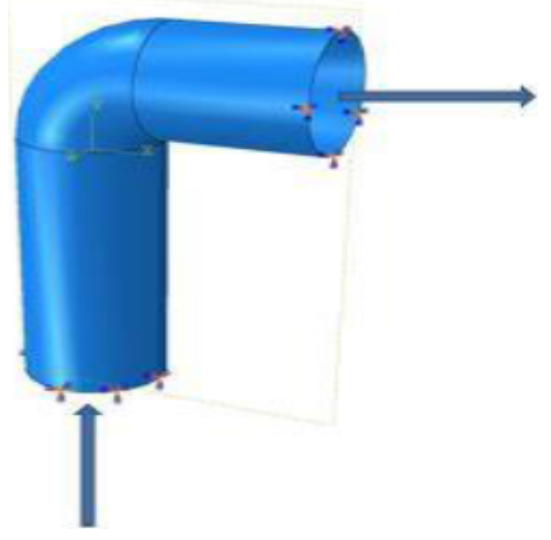

Figure 5: Graphical representation of flow direction.

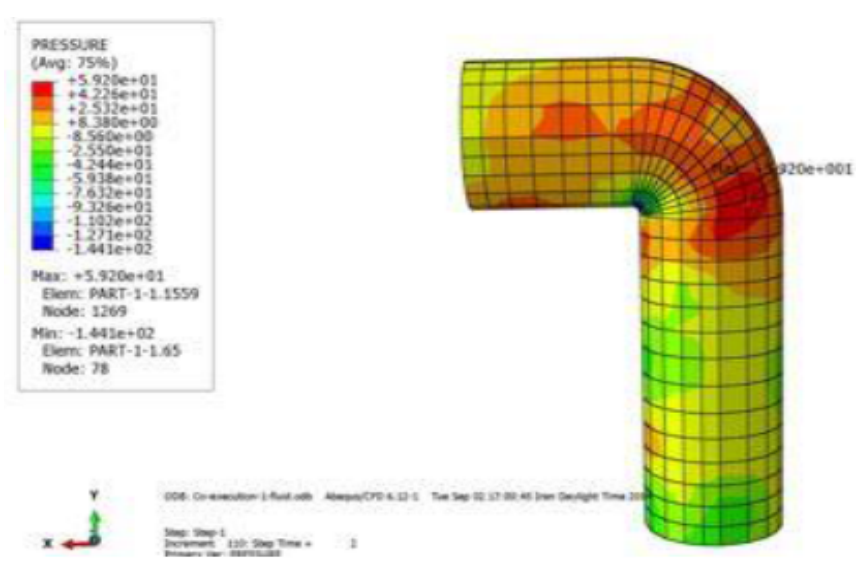

Figure 6: Pressure distribution in our 1st case.

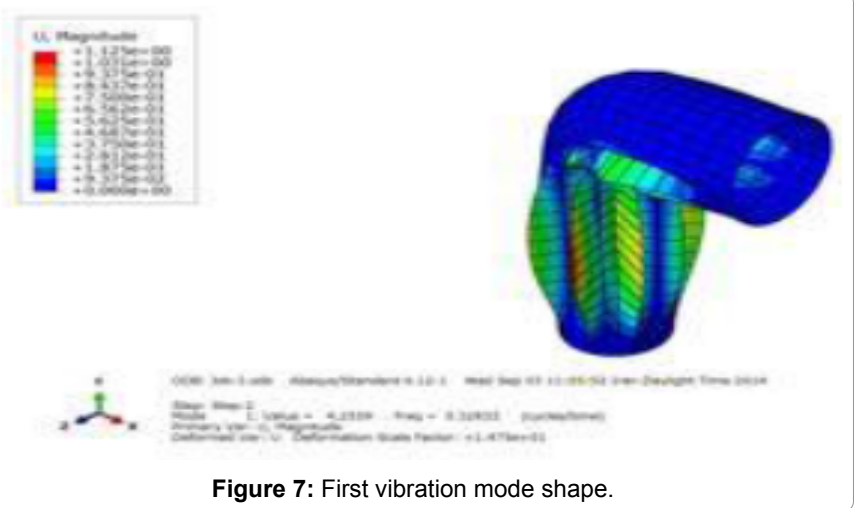

In this paper, we studied the dynamic effect and pressure distribution caused by fluid flow through an elbow pipe section, with a 90 degree bend. We fixed both ends of the elbow section to the walls so that it experiences zero displacement at end points. We then identified the location of critical points, in which the maximum and minimum pressure is implied on. Afterwards we investigated the effect of fluid velocity on the location and magnitude of these critical points. We also investigated the stress distribution caused by pressure fluctuations caused by the flow. In the next step, for each case of fluid velocity investigated we implied the calculated maximum and minimum pressure as an extensive pressure on the entire section body. And for each case we calculated the 


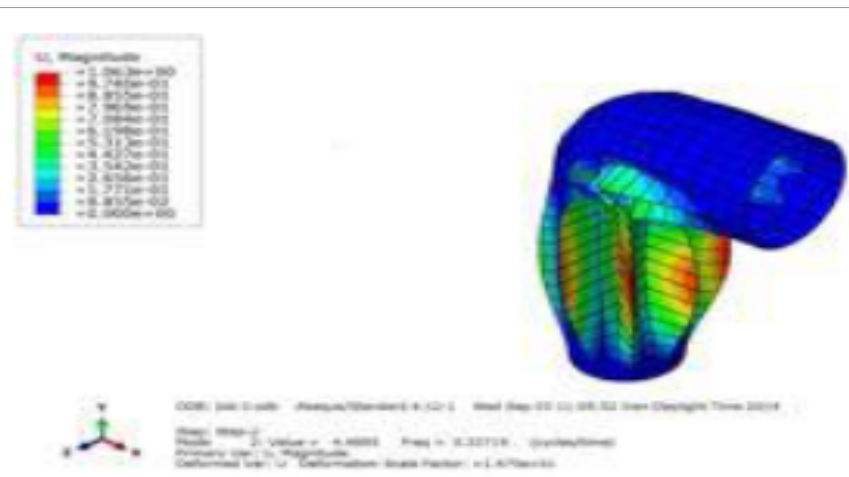

Figure 8: Second vibration mode shape.

frequency and vibration mode shapes caused by that pressure. Finally we concluded the effect of fluid flow velocity on the forced vibrations induced on the elbow pipe section [6-9].

\section{Modeling}

The fluid we considered in this study is water. Water, taking up almost $70 \%$ in volume of our planet, is the cheapest and most common fluid found on earth. Not surprisingly, it's the most common fluid used in industrial application. Water at $20^{\circ} \mathrm{C}$ has a density of approximately $1000 \mathrm{~kg} / \mathrm{m}^{3}$ and a dynamic viscosity of $1.002 \times 10^{-3} \mathrm{~N} . \mathrm{S} / \mathrm{m}^{2}{ }^{2}$ and a kinematic viscosity of $1.004 \times 10^{-6} \mathrm{~m}^{2} / \mathrm{S}$. We also know water is a Newtonian fluid and in this paper we considered it to be completely incompressible.

Abaqus as a CFD solver, we simulated a turbulent flow of water going through an elbow shaped pipe with a specific velocity, and being discharged at the end with atmospheric ambient pressure. The inside of the pipe shell is completely wetted by the flow and is completely water sealed, meaning we did not consider any mass diffusions inside the material. So that the fluid doesn't scape from the shell walls. The total length of the pipe is $190 \mathrm{~mm}$ and has a constant diameter of $45 \mathrm{~mm}$ and a shell thickness of $2 \mathrm{~mm}$. The pipe shell is considered to be a standard ST-37 homogeneous steel with below isentropic properties:

Elastic modules of $210 \mathrm{GPa}$, Plastic modules of $250 \mathrm{GPa}$, Poisson's ratio of 0.34 and a density of $7860 \mathrm{~kg} / \mathrm{m}^{3}$.

We modeled the fluid separately, in a fashion to fill the entire geometry of the pipe section, being same length as the pipe and having a diameter of $43 \mathrm{~mm}$ so that it exactly fits inside the pipe shell. To overcome the complex nature of fluid-solid interaction inside the pipe section, we had to split to flow process to different stages, and use different approaches for each different stage. For example we had to use a dynamic approach to calculate the pressure distributions at one stage, and then use a static approach to find vibration modes imposed by that pressure distribution. Then Standard explicit analysis was conducted on the shell body whilst fixing both ends so they experience zero displacement. To obtain the pressure distribution we had to use dynamic implicit analysis on the inside of the shell and to find the effect of the pressure gradient on the vibration modes we used a static general analysis. And finally to obtain the stress and strain distribution we used dynamic explicit analysis on the inside of the shell body. All of the analysis was done regarding Non-linear geometry applied and the simulation was held with $0.002 \mathrm{~s}$ time steps. The total fluid flow time inside the shell was considered to be 2 seconds. This was chosen appropriately to allow the flow to fully develop itself. For the cases studied we set the initial velocity of the fluid to be $0.2 \mathrm{~m} / \mathrm{s}, 0.5 \mathrm{~m} / \mathrm{s}, 0.7$ $\mathrm{m} / \mathrm{s}, 1 \mathrm{~m} / \mathrm{s}$ and $1.5 \mathrm{~m} / \mathrm{s}$ respectfully. No external forces were applied on the shell and the fluid is discharged to atmospheric ambient pressure environment. We can see the flow direction marked by the arrows in Figure 5.

The natural frequency of each vibration mode for our simulation is calculated shown in Table 1.

\section{Free Vibrations}

The elbow shell, being fixed at both ends has a degree of freedom (DOF) of zero. We anticipated small vibrations towards the entrance and exit of the section, but we knew largest vibrations will occur at the location of the bend. We later showed that the most displaced points were located exactly at the elbow bend, and the least displaced point were located towards the end sections of the shell. With the end points being fixed.

The pressure distribution for the first case, in which the fluid has a velocity of $0.2 \mathrm{~m} / \mathrm{s}$ is shown below. The maximum magnitude of pressure encountered is $59.2 \mathrm{MPa}$ and the minimum pressure encountered is $-144 \mathrm{MPa}$. The reason for sub-zero pressure distribution, is the secondary flow taking shape within the elbow section, causing a suction effect on the shell body. The pressure distribution for this case can be seen in Figure 6.

We found the pressure distribution and the two critical points for other cases as well. But only demonstrated the graphical representation of the first case here.

We simulated the first 5 vibration mode shapes for each case. Carefully analyzing these shapes, we denote that for higher vibration modes, the shapes brake into more corners and angles. We found out by increasing the fluid velocity, the frequency for each vibration mode will increase, resulting in more corners and angles in its shape. For each case we calculated the maximum encountered pressure and tabulated them below (Figures 9-13).

For example, the first, second and thirds vibration mode shape of the first case $(0.2 \mathrm{~m} / \mathrm{s}$ fluid velocity) is shown in Table 2 .

\section{Forced Vibrations}

We investigated the maximum and minimum pressure fluctuations over the 2 second time period of the whole simulation. In the diagram below, you can see pressure-time changes for the critical points of the second case $(0.5 \mathrm{~m} / \mathrm{s}$ fluid velocity). It can be seen that the minimum pressure magnitude fluctuation range is more widely fluctuating than that of the maximum pressure, making it more important to take note of a stress-time fluctuation graph, based on the von-misses stress criterion. One can easily see, the moments when pressure magnitude strikes up, the stress magnitude follows. Showing the direct relation between pressure fluctuations and stress fluctuations imposed by pressure change. The graph below shows data for our third case $(0.7 \mathrm{~m} / \mathrm{s})$.

We identified the exact location of the critical point which experiences the maximum pressure for each case, then we followed that

\begin{tabular}{|c|c|c|}
\hline Index & Mode value & Mode vibration \\
\hline 1 & 4.0581 & $0.32061 \mathrm{~Hz}$ \\
\hline 2 & 4.2921 & $0.32973 \mathrm{~Hz}$ \\
\hline 3 & 4.7978 & $0.34861 \mathrm{~Hz}$ \\
\hline 4 & 5.4132 & $0.37029 \mathrm{~Hz}$ \\
\hline 5 & 5.8002 & $0.38330 \mathrm{~Hz}$ \\
\hline
\end{tabular}

Table 1: Natural frequency vibrations and mode Eigen value. 


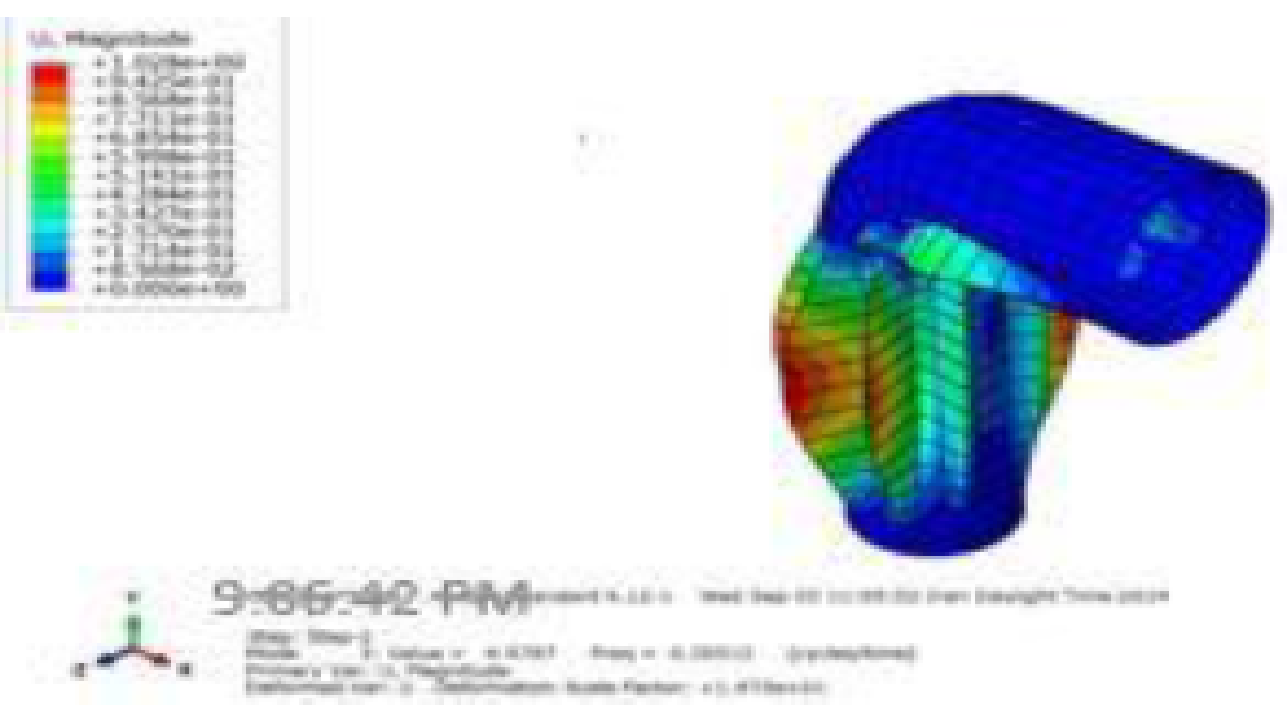

Figure 9: Third vibration mode shape.

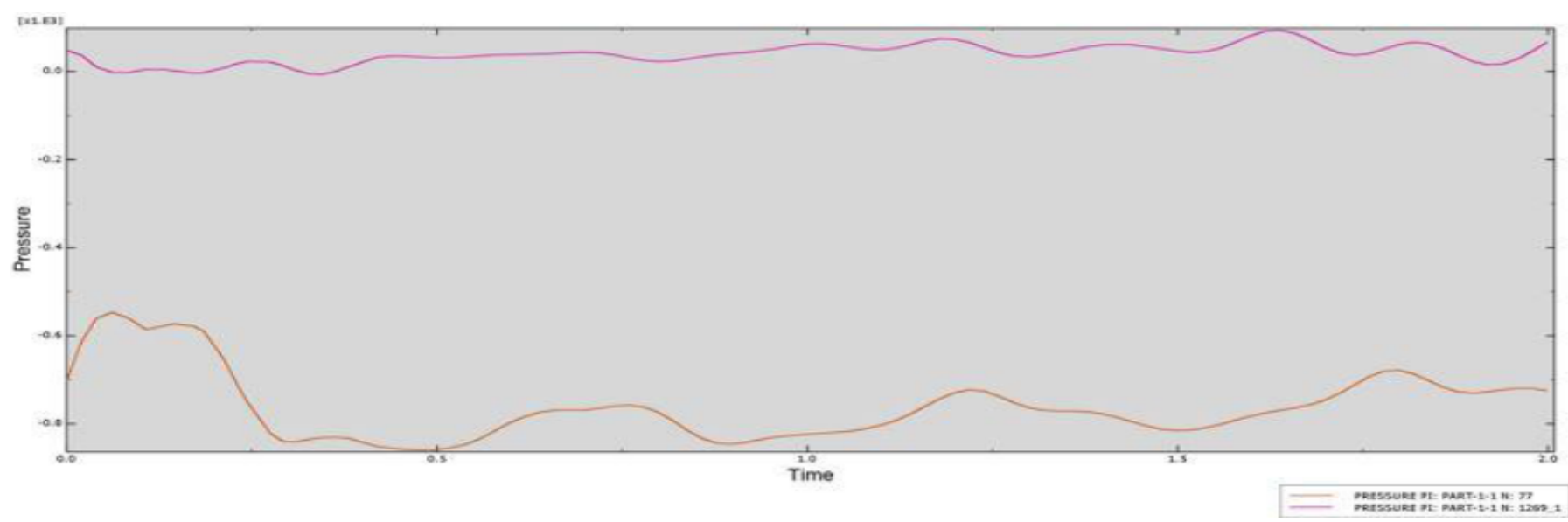

Figure 10: Maximum and minimum pressure vs. time for second case $(0.5 \mathrm{~m} / \mathrm{s})$
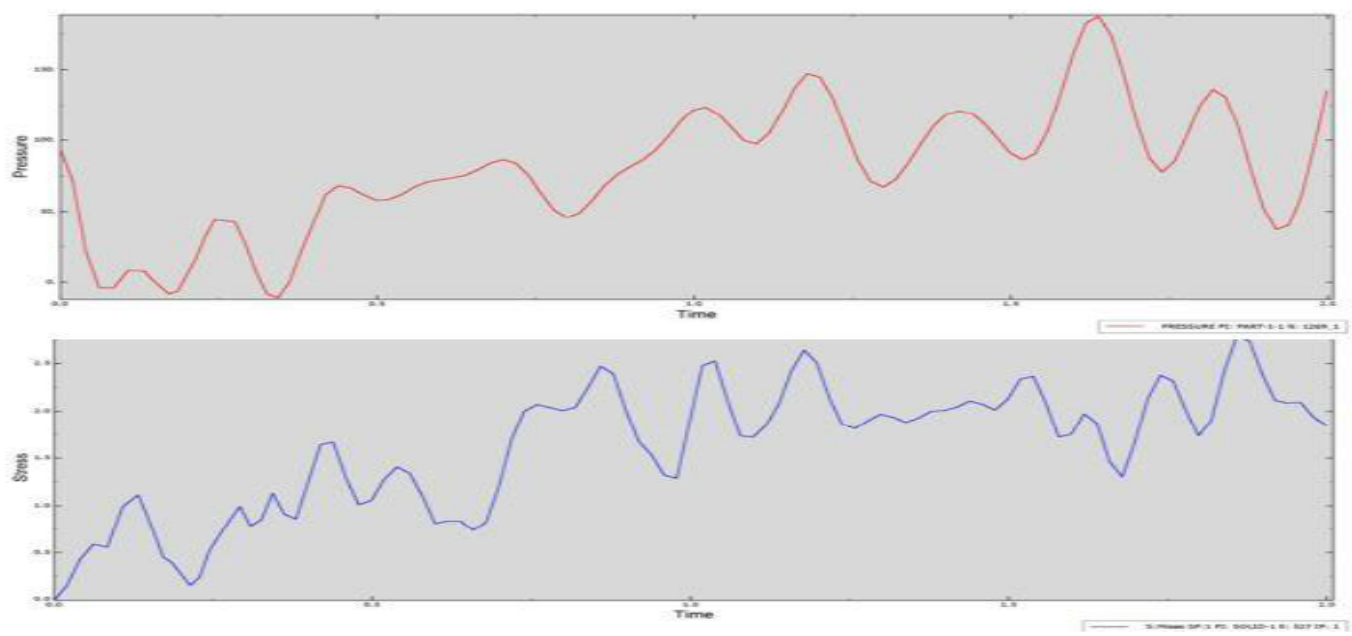

Figure 11: Pressure and stress vs. time for third case $(0.7 \mathrm{~m} / \mathrm{s})$. 


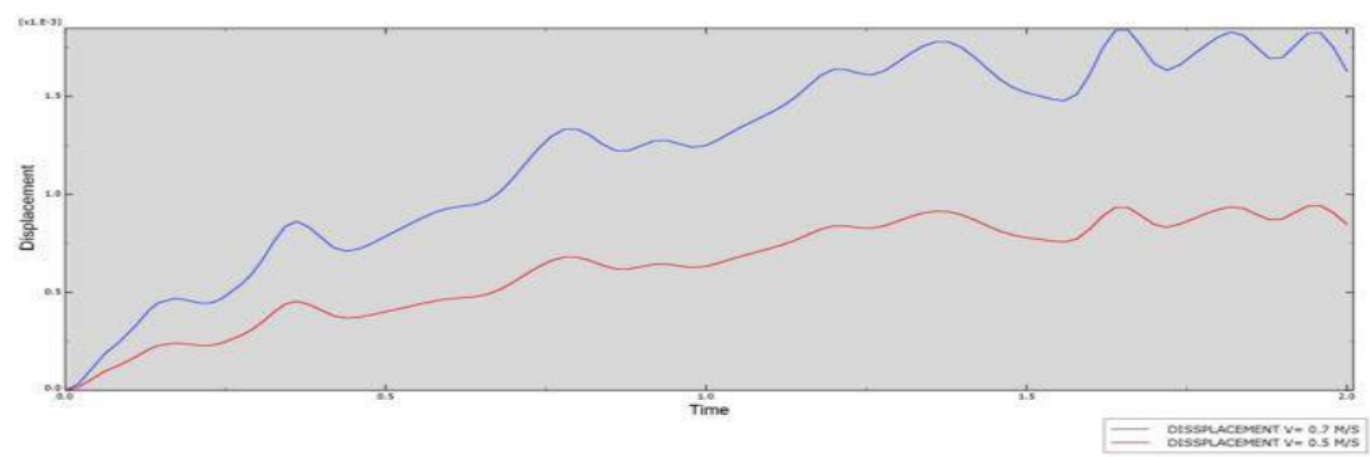

Figure 12: Displacement of critical point in second and third case $(0.5 \mathrm{~m} / \mathrm{s}$ and $0.7 \mathrm{~m} / \mathrm{s})$.

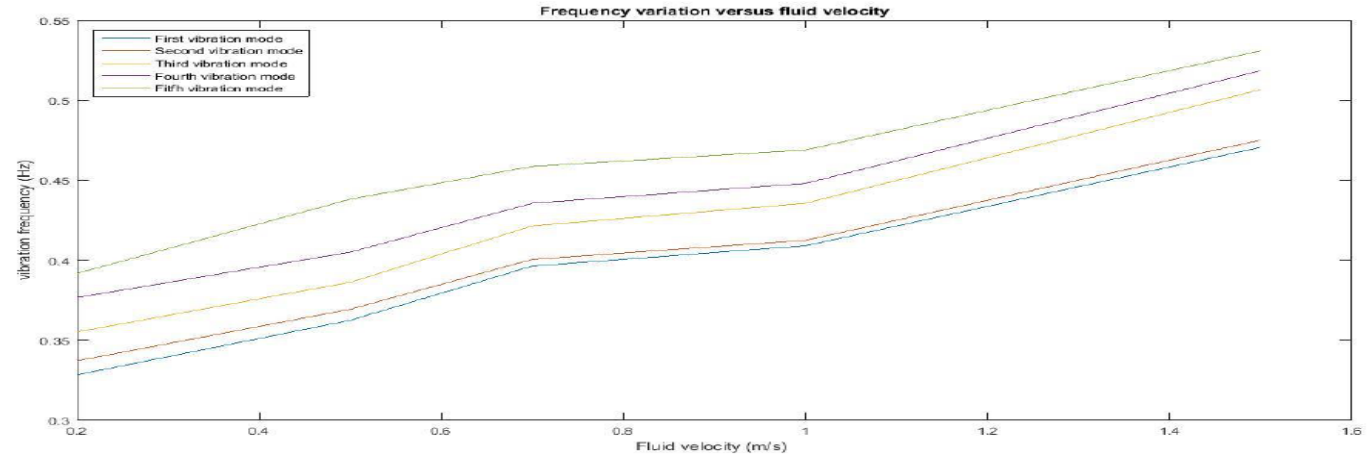

Figure 13: Vibration frequency vs. fluid velocity.

\begin{tabular}{|c|c|}
\hline $\begin{array}{c}\text { Maximum encountered pressure } \\
\text { (MPa) }\end{array}$ & Fluid velocity $\mathbf{( m / s )}$ \\
\hline 59.2 & 0.2 \\
\hline 346 & 0.5 \\
\hline 682 & 0.7 \\
\hline 825 & 1 \\
\hline 1720 & 1.5 \\
\hline
\end{tabular}

Table 2: Maximum pressure against fluid velocity.

point through time to investigate the displacements which that exact point experiences. For the second and third case $(0.5 \mathrm{~m} / \mathrm{s}$ and $0.7 \mathrm{~m} / \mathrm{s}$ fluid velocity), we calculated the displacement versus time graph of the critical point as shown in graph below From Figure 12, it can be seen at the exact same moment's pressure and stress increase in magnitude, the critical point studied experiences a sudden displacement. The changes in displacement of the point through the time period, represents its vibration. Thus one could relate the pressure/stress fluctuations with the change in displacement of that point and the vibrations caused by them. This displacement can also be referred to as deformation, as it tends to change the position of the points, deforming the geometry of the shape. By carrying out simulation for the rest of the cases, we found out the maximum displacement of the critical point for each case and tabulated them as shown in Table 3.

\section{Results and Conclusion}

In this paper, we showed our investigation on different vibration frequency modes caused by different cases of fluid flow with different velocity. We concluded that by increasing the fluid velocity, the inflicted vibrations will increase in frequency. This is shown in Table 4. Considering the natural frequency for our simulated elbow pipe, we

\begin{tabular}{|c|c|}
\hline $\begin{array}{c}\text { Maximum displacement of critical } \\
\text { point }(\mathbf{m m})\end{array}$ & Fluid velocity $\mathbf{( m / s )}$ \\
\hline $1.20 \times 10^{-3}$ & 0.2 \\
\hline $8.29 \times 10^{-3}$ & 0.5 \\
\hline $1.70 \times 10^{-2}$ & 0.7 \\
\hline $3.51 \times 10^{-2}$ & 1 \\
\hline $1.39 \times 10^{-1}$ & 1.5 \\
\hline
\end{tabular}

Table 3: Displacement against fluid velocity.

conclude that there is a chance for a vibration resonance to occur at speeds near $0.2 \mathrm{~m} / \mathrm{s}$. As the vibrations induced on this case are closer to that of the natural vibration frequency of our pipe regarding its material properties. So, if we were to build such a pipe with the mentioned properties, we have to be careful to not let the fluid velocity drop below $0.2 \mathrm{~m} / \mathrm{s}-0.3 \mathrm{~m} / \mathrm{s}$ which could encourage vibration resonance to take place. By plotting these data onto a graph for each case, we showed the vibration frequency of each mode. The lines graphed below represent the cases for each velocity. An intersection in between these lines would represents a phenomenon called 'flattering' which basically means the fluid velocity has reached its critical value inside the pipe, and could cause devastating damage on the pipe body by induced vibrations.

In the scenario we simulated, the lines of constant velocity do not intersect. Thus, did not encounter the 'flattering' phenomena in our simulation. We also showed that by increasing fluid flow velocity, the maximum pressure and stress distribution on the pipe section will increase in both magnitude and effected area. The effect of increasing stress on the section, causes an increase in maximum displacement of the effected point. The variation in displacement of that point through 
Citation: Keshtkar H, Jafari AA (2017) Vibration Analysis of a Turbulent Fluid Passing Inside an Elbow Shaped Pipe Section. J Appl Mech Eng 6: 273. doi: 10.4172/2168-9873.1000273

Page 6 of 6

\begin{tabular}{|c|c|c|c|c|}
\hline Fluid velocity & $\begin{array}{c}\mathbf{1}^{\text {st }} \text { vibration } \\
\text { mode }\end{array}$ & $\begin{array}{c}\mathbf{2}^{\text {nd }} \text { vibration } \\
\text { mode }\end{array}$ & $\begin{array}{c}\mathbf{3}^{\text {rd }} \text { vibration } \\
\text { mode }\end{array}$ & $\begin{array}{c}\mathbf{4}^{\text {th }} \text { vibration } \\
\text { mode } \\
\text { mode }\end{array}$ \\
\hline $0.2 \mathrm{~m} / \mathrm{s}$ & $0.3282 \mathrm{~Hz}$ & $0.3371 \mathrm{~Hz}$ & $0.3551 \mathrm{~Hz}$ & $0.3766 \mathrm{~Hz}$ \\
\hline $0.5 \mathrm{~m} / \mathrm{s}$ & $0.3624 \mathrm{~Hz}$ & $0.3693 \mathrm{~Hz}$ & $0.3917 \mathrm{~Hz}$ & $0.4050 \mathrm{~Hz}$ \\
\hline $0.7 \mathrm{~m} / \mathrm{s}$ & $0.3963 \mathrm{~Hz}$ & $0.4005 \mathrm{~Hz}$ & $0.4281 \mathrm{~Hz}$ & $0.4356 \mathrm{~Hz}$ \\
\hline $1 \mathrm{~m} / \mathrm{s}$ & $0.4090 \mathrm{~Hz}$ & $0.4124 \mathrm{~Hz}$ & $0.4214 \mathrm{~Hz}$ & $0.4480 \mathrm{~Hz}$ \\
\hline $1.5 \mathrm{~m} / \mathrm{s}$ & $0.4706 \mathrm{~Hz}$ & $0.4751 \mathrm{~Hz}$ & $0.4356 \mathrm{~Hz}$ & $0.468 \mathrm{~Hz}$ \\
\hline
\end{tabular}

Table 4: Fluid velocity against induced vibrations.

time, causes it to vibrate. The greater the displacement rates, the greater the vibration frequency.

\section{References}

1. Garrison WG (1988) Major fires and explosions analyzed for 30-year project. Hydrocarbon Process 67: 9

2. Klosowski P, Woźnica K, Weichert D (1995) Dynamic of elasto-viscoplastic plate and shells. Archive of Applied Mechanics 65: 326-345.

3. Qatu MS (2002) Recent advances in the dynamic behaviour of shells: 19892000. Appl Mech Rev 55: 325-350.

4. Abraham RAB (1998) An investigation into the vibration and stability of pipe conveying fluid with multi comliant $\mathrm{N}$-span boundary conditions, Baghdad University.

5. Chen DY, Ren BS (1998) Finite element analysis of the lateral vibration of thin annular and cicular plates with variable thickness. J Vib Acoust 120: 747-752.

6. Kalpakli (2012) Experimental study of turbulent flows through pipe bends.

7. Atkins KE (1990) Pipe vibration analysis, Nineteeth Turbomachinery Symposium.

8. Teixeira V, Dias Rodrigues J, José Melo F, Carneiro JO (2005) The modeling analysis of a pipe elbow with realistic boundary conditions. Int $\mathrm{J}$ Pressure Vessels and Piping: 593-601.

9. Al-Hilli H (2013) Free vibration characteristics of elastically supported pipe conveying on fluid. Nahrain University 16: 9-19. 